\title{
Assessment of proposed business plans of on-trip and pre-trip information in the LRT system (public urban transit) of the city of Zagreb
}

\author{
I. Ćavar, D. Barić \& Z. Kavran \\ Faculty of Transport and Traffic Sciences, University of Zagreb, Croatia
}

\begin{abstract}
The quality of public urban transit organization depends to a great extent also on the organization and the quality of on-trip and pre-trip information services. The aim of this service is to provide relevant, accurate and usable traffic and transport information to current users of the public urban transit, as well as to attract new users, alleviating the burden on the roads and insuring high-quality transport service to motorists who at least on one section of their trip use public transport means. Apart from classical information forms this system greatly relies also on new telecommunication technologies including the third generation of mobile networks and mobile Internet.

Apart from the wide range of methods of collecting information, their processing and dissemination, the entire problems of introducing the mentioned services into the newly organized system such as LRT needs to be systemically analyzed. It is especially important to analyze in advance and to define the relations between the private and public sector in the described process. The paper considers the corporate plans of organizing the system of on-trip and pretrip information in the LRT system applicable in the City of Zagreb. Their implementability has been evaluated by a professional team defining the relevant factors in the selection of the corporate plan.
\end{abstract}

Keywords: on-trip and pre-trip information, multi-criteria decision-making, corporate plan, LRT - light rail transit, ITS - intelligent transportation systems. 


\section{Introduction}

In designing and introducing any new system into operation it is necessary to carefully consider all its elements and make strategic decisions on its implementation and organization.

As part of introducing the LRT system in the City of Zagreb (capital of the Republic of Croatia), with making of the master plan, defining of line routes, locations of stops and stations, organization of Park\&Ride system, etc. it is necessary to consider also the implementation of a number of additional services that will facilitate the usage and attract the users to the new LRT system [1]. The pre-trip and on-trip information is included in such services.

The usage of the public transit is in significant correlation with the quality of providing relevant, accurate and usable traffic and transport information by means of pre-trip and on-trip information services for the public transit users, including the motorists who at least in one part of their trip use the public transport means.

The pre-trip and on-trip information system (PPI) consists of the subsystem of pre-trip information before the start of the journey (when the user makes the decision on the mode selection to the destination, route, time of start and additional services) and the information system during the trip which includes usage of LRT on the way from the origin to destination. Its main characteristic is to attract new users to the system by providing the necessary information at the right moment so as to make their travelling as efficient and comfortable as possible.

The classical method of informing the passengers - users of the public transit are schedules and the accompanying service information for the passengers at the main terminals i.e. individual stations and stops. New methods of informing passengers include also the application of new ICT (information and communication technology) including the third generation of mobile networks and mobile Internet.

\section{Business plans}

In the widest sense the system for providing on-trip and pre-trip information services is divided into three phases: data collecting, consolidating and communicating. The method of organizing the realization of these three phases differs from system to system offering cooperation and overlapping of the private and public sector together with the service users. Most often it is a kind of a form of partnership including public-public and public-private partnerships.

When designing the system it is most important to define the very purpose of implementation (e.g. whether one wants to provide the users with a larger source of information, providing more numerous possibilities of selecting the travelling method or are the information to be used in TMC - traffic management center so that the traffic experts could improve the organization of transport).

Therefore, the business plans are designed with the aim of maximally efficient implementation of pre-trip and on-trip information services. 


\section{The business plan structure}

This paper deals with the comparison of different business plan structures [2] with defined flows of information and means between single elements. The purpose of the considered system of pre-trip and on-trip information is to provide the LRT system users with the necessary information in order to optimize their trips and in order to attract new users to the system.

Every structure encompasses the basic participants and the provision of the same set of services. The structures differ in the role of the information consolidator, users service provider and method of acquiring the information (one's own organization or information purchased from somebody else).

The basic presentation of structures as well as a short description are given further in the text.

\subsection{Public-centred operations}

Public-centred operations (Figure 1) structure gives highest importance to the public sector giving it the role of the biggest controller of the total system. The success of functioning of such a system depends to a great extent on the motivation of the public sector. The public sector delivers to the users for free a large volume of data, and the private sector that joins in the provision of pre-trip and on-trip information has to independently collect the additional volumes of data in order to compete on the service market.

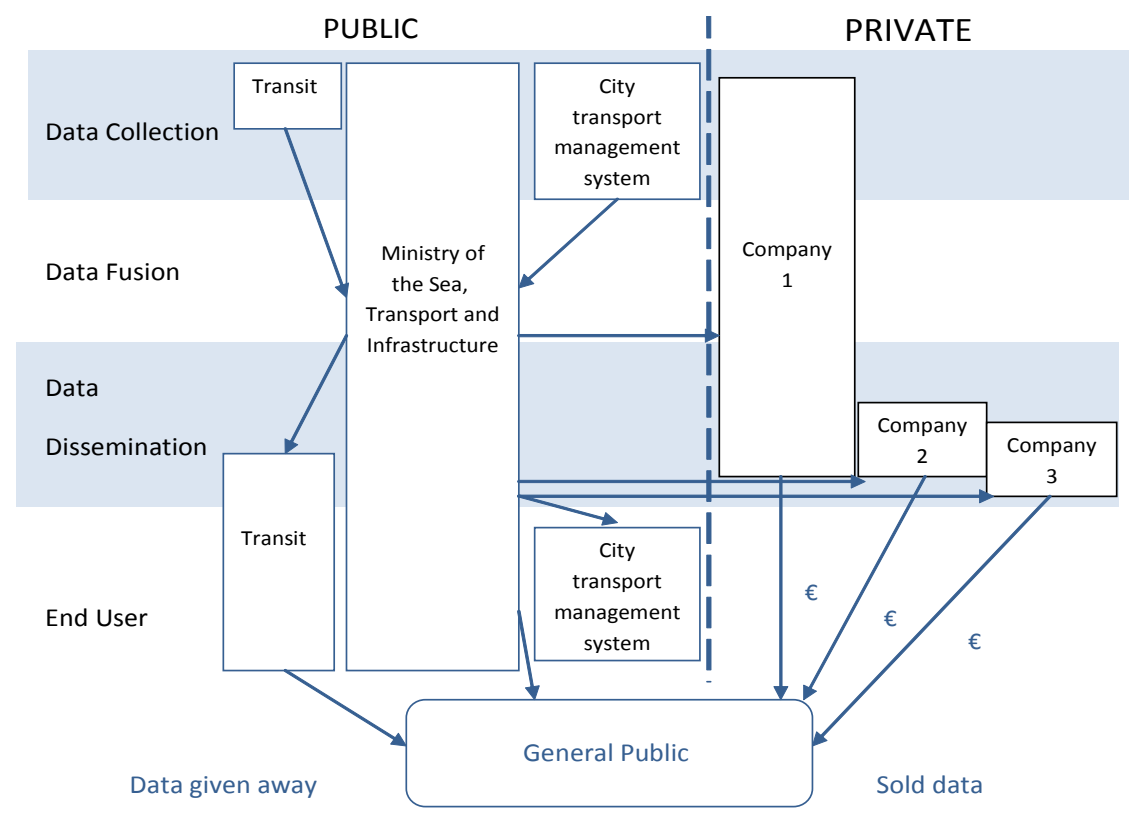

Figure 1: Public-centred operations. 


\subsection{Contracted operations}

Contracted operations (Figure 2) represents the organization structure in which the influence of the public sector is still the greatest, but the role of the private sector in certain elements has been changed. During data consolidation the public sector retains the control leaving the contractual private partners to carry out the data fusion process by applying their program tools.

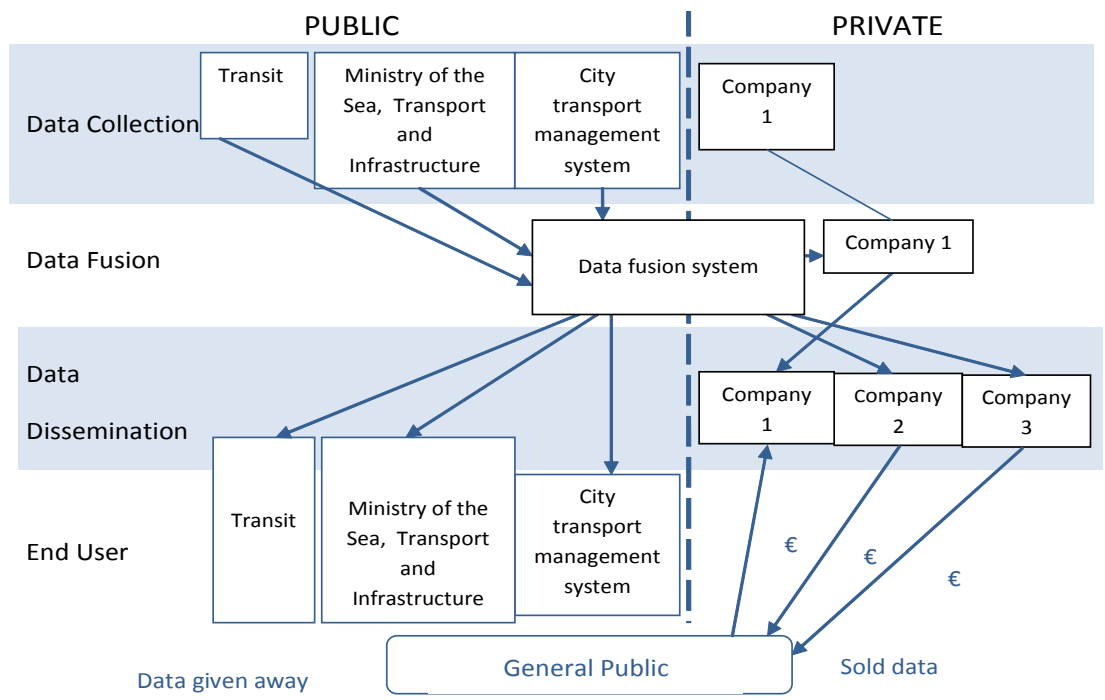

Figure 2: Contracted operations.

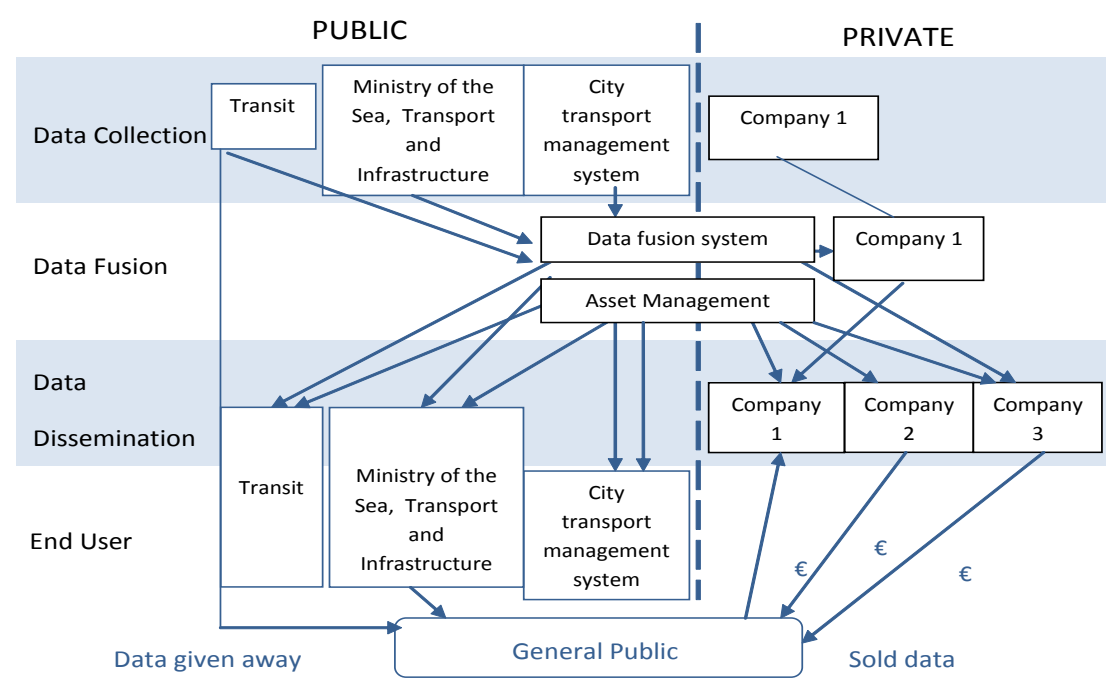

Figure 3: Contracted fusion with asset management. 


\subsection{Contracted fusion with asset management}

Contracted Fusion with Asset Management (Figure 3) represents the extension of the Contracted operations of the structure with a reduced volume of data that the users obtain for free. Also, the novelty is the role of asset management that has the aim of combining the product development in order to provide a product that meets the users' requirements. Apart from this function the asset management is also in charge of selling the service to the users.

\subsection{Franchise operations}

Franchise Operations (Figure 4) understands exclusion of the public sector from the data consolidation process, leaving this role to a private company that forwards the data to other participants. Part of the data returns back to the public sector in order to deliver them free to the users, whereas other firms are additionally charged for the consolidated data.

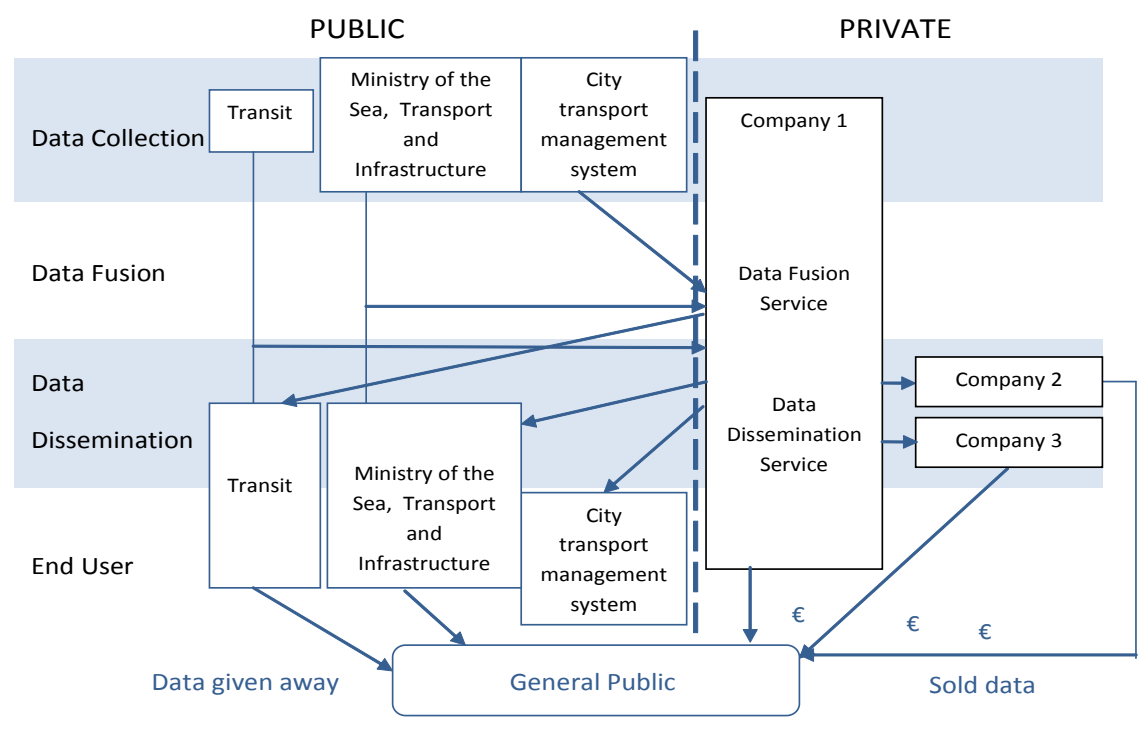

Figure 4: Franchise operations.

\subsection{Private, Competitive Operations}

Private, Competitive Operations (Figure 5) encompasses the biggest participation of the private sector maximizing the competitiveness among the companies with the aim of reducing the price for the end user of the service. Several companies are included in the data fusion procedure, and add value to the basic data depending on their business orientation. 


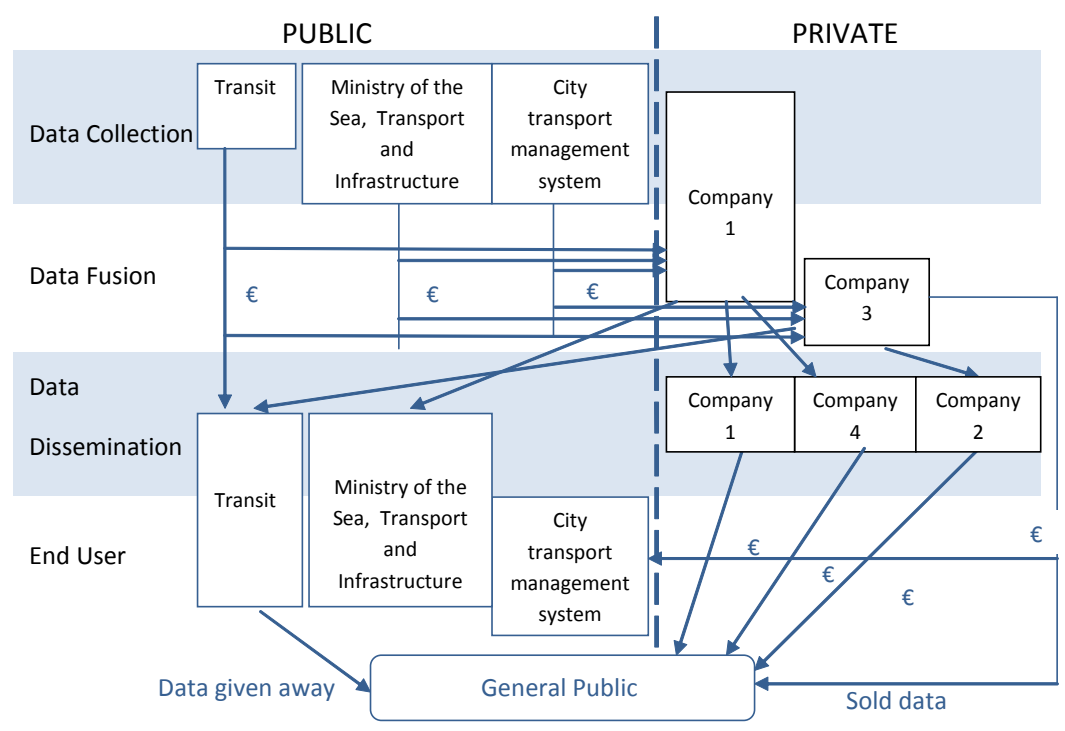

Figure 5: $\quad$ Private, competitive operations.

\section{Criteria for business plan structure selection}

The function of the PPI system is to ensure the availability and the user-friendly usage of information in order to make decisions on the destination, method of tavelling, route, travel time, usage of additional facilities, etc. It is necessary to consider the expressed and non-expressed users' requirements, and the feasibility of the proposed models on the given problem. LRT is a system of public urban transit with the defined access points and the aim of improving the functioning of the overall complex urban traffic system. The access and delivery of information to the users can be done in numerous ways [3]

The users' requirements for PPI services are:

- the system should provide all the LRT users and traffic participants information on emergency services and information on the dangers (free of charge);

- $\quad$ the system has to be able to charge the users a certain fee for providing information that are not urgent i.e. not provided by emergency services;

- the system should provide the users with correct, updated and easy-tounderstand information that are of benefit to the LRT users;

- the system should provide information on alternative routes (faster, shorter, cheaper, etc.);

- the system should allow the users to plan their trip on their own based on their own criteria;

- the system should allow the users to plan the trip taking into consideration their restrictions (users with special needs i.e. disabled persons); 
- the system should provide information on other available transport modes due to disruptions in the system functioning (adverse weather conditions, strikes, cultural or sport events, etc.);

- the system should provide real-time and forecast information for the entire area covered by LRT and the public transit system;

- the system should provide additional information required by the userfares, forecast incident situations, works on the infrastructure, etc.

The above mentioned leads to the definition of the criteria and their subcriteria in the selection of the corporate structure of the PPI system:

- adaptability of the model to LRT system

$\circ$ compatibility with the existing information systems in public urban transit

○ possibility of improving and continuous system development

- level of satisfaction of the users' requirements

- acceptable amount of investments into the system construction

- motivation of the stakeholders for the implementation of single models

- motivation of the public sector

$\circ$ motivation of the private sector

\section{Multi-criteria decision-making}

In accordance with the defined criteria and subcriteria the analytic hierarchic process (AHP) will be applied as the method of multi-criteria decision-making.

AHP is based on the analysis of the problem into a hierarchic structure (Figure 6) so as to simplify the perception of the entire problem and increase the consistency of evaluating the elements.

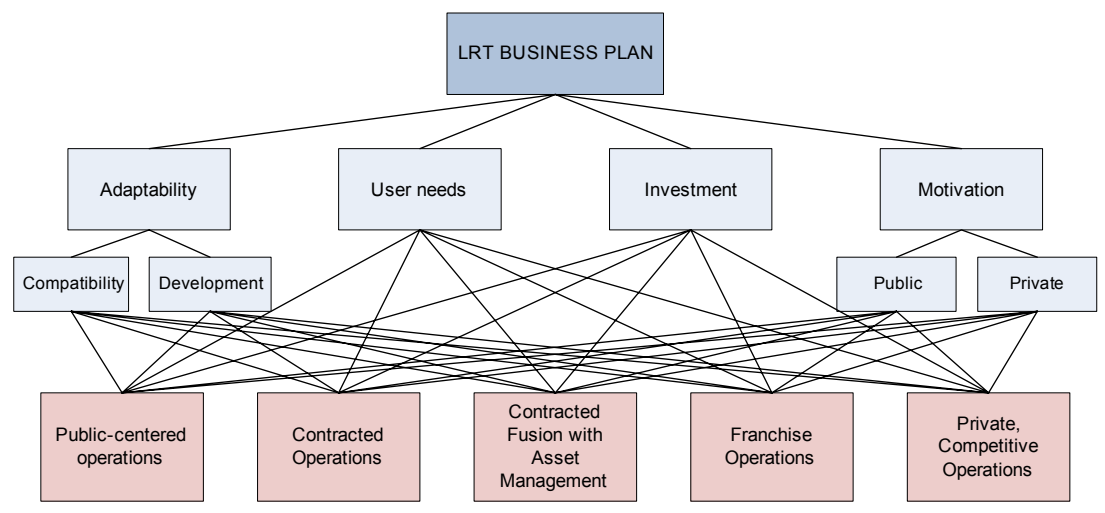

Figure 6: Hierarchic structure of the problem.

The most important theoretical assumption of the hierarchic process is the comparison of the alternatives in pairs. The comparison of pair-wise elements yields much more precise and realistic insight into their relations than in comparing several elements at a time [5]. 
The selection of the scale for the comparison of elements should be based on the following considerations:

1. the scale must be able to express human differences in the feelings when assessments are made.

2. if the scale values are marked with $\mathrm{x}_{1}, \mathrm{x}_{2}, \ldots, \mathrm{x}_{\mathrm{p}}$, then the following should be valid $\mathrm{x}_{\mathrm{i}+1}-\mathrm{x}_{\mathrm{i}}=1$, and $=1, \ldots, \mathrm{p}-1$.

Based on the defined elements for comparison the Saaty scale of importance is applied [4].

Another important segment is the development of quantitative techniques and methods for processing the data obtained by comparison. The very process of calculation is based on the theory of matrices with included elements of calculating eigenvalue and eigen vector [6].

The mathematical procedure for defining the criteria priority vectors is identical to the procedure of determining the priorities of alternatives within certain criteria. The vector obtained as a result of the criteria priority calculation is marked with $\mathrm{k}$.

$$
\mathrm{k}=\left[\mathrm{k}_{1}, \mathrm{k}_{2} \ldots \mathrm{k}_{\mathrm{m}}\right]
$$

Matrix B is formed so that the first column has the vector of priorities of alternatives regarding the first criterion $\mathrm{w}_{1}$, the second column is the priority vector regarding the second criterion $\mathrm{w}_{2}$ and so on, for all the $\mathrm{m}$ criteria. Matrix $\mathrm{B}$ has dimensions $\mathrm{n} \times \mathrm{m}$, i.e. it has as many rows as there are alternatives and as many columns as there are criteria.

$$
\mathrm{B}=\left[\mathrm{w}_{1}, \mathrm{w}_{2} \ldots \mathrm{w}_{\mathrm{m}}\right]
$$

Linear combination of vectors $\mathrm{w}_{1}, \mathrm{w}_{2}, \ldots, \mathrm{w}_{\mathrm{m}}$ and vector components $\mathrm{k}, \mathrm{k}_{1}$, $\mathrm{k}_{2}, \ldots, \mathrm{k}_{\mathrm{m}}$ yield vector $\mathrm{p}$ that represents the final priority.

$$
\mathrm{p}=\mathrm{k}_{1} \cdot \mathrm{w}_{1}+\mathrm{k}_{2} \cdot \mathrm{w}_{2}+\ldots+\mathrm{k}_{\mathrm{m}} \cdot \mathrm{w}_{\mathrm{m}}=\left[\begin{array}{llll}
\mathrm{p}_{1} & \mathrm{p}_{2} & \ldots & \mathrm{p}_{\mathrm{n}}
\end{array}\right] \mathrm{T}
$$

The elements of vector $\mathrm{p}$ are coefficients of the total priority of alternatives, so that $\mathrm{p}_{1}$ represents the coefficient of the total priority of the first alternative in relation to the objective, $\mathrm{p}_{2}$ is the coefficient of total priority of the second alternative in relation to the objective, $p_{n}$ coefficient of the total priority of the $\mathrm{n}$-th alternative in relation to the objective. Based on these values the alternative is selected which represents the selection of the business plan for the PPI subsystem in the LRT system.

In order to monitor the consistency in realizing the comparison procedure and calculation of priorities in assessment the index of consistency has been defined in the following form:

$$
\frac{\lambda_{\max }-n}{n-1}
$$

Where $\lambda_{\max }$ is eigenvalue and $n$ is number of alternatives. When strict consistency is achieved the consistency coefficient will be zero, and in case of complete lack of consistency the coefficient will be one, i.e.

$$
0 \leq \text { consistency coefficient } \leq 1
$$




\section{Model results}

In accordance with the described methodology, the hierarchic elements have been compared and based on expression (3) the final priorities of alternatives have been determined (Figure 7).

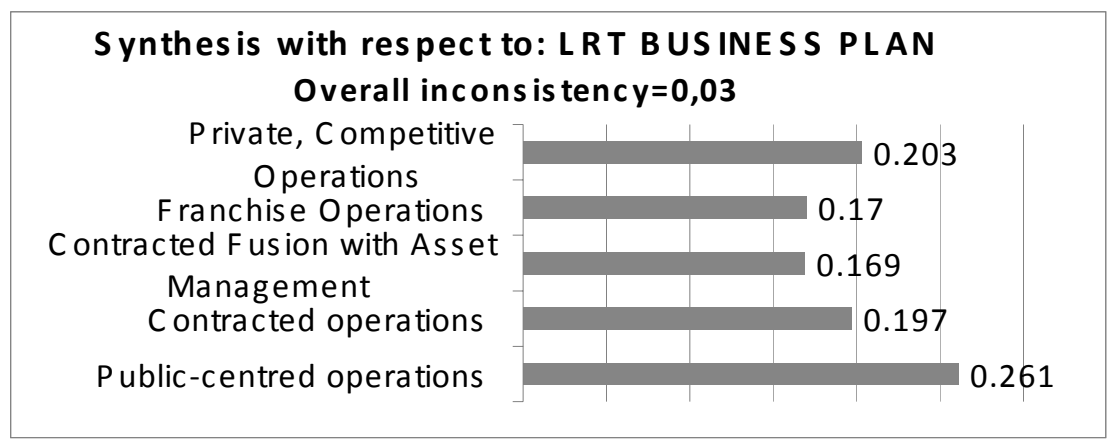

Figure 7: Priorities of business plans.

It can be seen that the highest priority belongs to public-centred operations structure of the business plan (26.1\%) which is the most acceptable for the initial phase of the LRT system development. It is followed by the private, competitive operations (20.3\%) structure, and then by contracted operations (19.7\%), franchise operations $(17.0 \%)$ and contracted fusion with asset management $(16.9 \%)$.

\section{Conclusion}

In introducing a new system into operation, such as e.g. the LRT system in the City of Zagreb, it is necessary to make strategic planning of all its subsystems. PPI represents the dynamic market of services that have the aim of timely and adequate provision of information to the system users in order to provide as efficient and as comfortable usage of LRT as possible. Among different structures of the PPI system business plan the most acceptable solution in the initial phase was found to be the public-oriented structure. Taking into consideration that LRT is a public urban transit system, the tendency for the public sector to keep the dominance over this service is understandable. The next acceptable solution is the structure of private, competitive operations of the business plan (which represents a diametrically opposite structure to the publicoriented structure) placing strongest emphasis on the role of the private sector and the market competition in the organization of the PPI system activities. If implemented as a solution in this phase of system construction, the publicoriented structure is expected to evolve over time and to let go more and more of the business to private companies. Of course, the intensity of this process would depend most of all on the motivation of the private sector to take over the leading 
roles and the willingness of the public sector to let go of this part to private companies.

\section{References}

[1] Group of authors: Research of underground - overground rail system in the City of Zagreb, Project results, Faculty of Transport and Traffic Sciences, University of Zagreb, 2006.

[2] Gilroy, R., Puentes, R., Schuman, R.: Choosing the Route to Traveler Information Systems Deployment, Intelligent Transportation Society of America, Advanced Traveler Information Systems Committee, Washington, pp. 41-50, 1998.

[3] Vujić, M., Ćavar, I., Bošnjak, I., Distribution of travel information and driver's perception, Proc. Of the ISEP 2006, eds. T. Maher, M. Anžek et al., Ljubljana, Slovenia,pp.135-143, 2006.

[4] Saaty, T. L.: Decision Making for Leaders, RWS Publications, Pittsburgh, Pennsylvania, 315 pp., 1996.

[5] Ćavar, I., Model izbora mobilnog uređaja u Republici Hrvatskoj primjenom AHP metode, diploma thesis (in Croatian), FPZ, University of Zagreb, Zagreb, pp.8-20, 2003. 